Maciej SZKODA, Grzegorz KACZOR

Cracow University of Technology (Politechnika Krakowska)

\title{
APPLICATION OF THE FMEA METHOD FOR THE RISK ASSESSMENT IN RALIWAY TRANSPORT ACCORDING TO THE REQUIREMENTS OF PN-EN IEC 60812:2018-12 STANDARD
}

\section{Zastosowanie metody FMEA do oceny ryzyka w transporcie kolejowym zgodnie $\mathrm{z}$ wymaganiami normy PN-EN IEC 60812:2018-12}

\begin{abstract}
The paper presents the procedure of performing the safety assessment using the FMEA (Failure Mode and Effects Analysis) method, according to the latest version of the PN-EN IEC 60812:2018 standard. The attention was paid to the application of the method for the assemblies and subassemblies of rail vehicles, for which it is increasingly used. The example used in the following paper refers to the fire protection system of a rail vehicle that meets the requirements of the PN-EN IEC 60812:2018 standard. Performing the risk assessment at the design stage of railway products is a part of the customer's requirements and is a key factor in the certification and placing them in service.
\end{abstract}

Keywords: FMEA, safety assessment, rail vehicles

Streszczenie: $W$ artykule opisano procedure postępowania podczas oceny ryzyka z zastosowaniem analizy przyczyn i skutków uszkodzeń FMEA, zgodnie z najnowszym wydaniem normy PN-EN IEC 60812:2018. W pracy zwrócono uwage na zastosowanie analizy dla zespotów i podzespołów pojazdów szynowych, w przypadku których jest ona coraz częściej wykorzystywana. Przyktad zastosowania metody FMEA przedstawiono dla systemu kontroli $i$ ograniczenia rozprzestrzeniania się pożaru pojazdu szynowego, spetniajacego wymagania normy PN-EN IEC 60812:2018. Wykonywanie oceny ryzyka na etapie projektowania podzespołów pojazdów kolejowych jest kluczowym czynnikiem $w$ procesie certyfikacji i wprowadzenia do eksploatacji.

Słowa kluczowe: analiza FMEA, ocena bezpieczeństwa, pojazdy szynowe 


\section{Introduction}

Failure Mode and Effects Analysis plays an important role in the purposes of accumulating evidence for compliance with product safety requirements (vehicles, infrastructure, railway signalling), especially at the design stage. Is a proposed tool in the RAMS procedure according to the standard [5]? It is a systematic approach to identify the causes and effects of potential failures at the local (subassembly) and global (system) levels. This method requires the involvement of an interdisciplinary team of the various specialists (constructors, safety engineers, analysts, others) who, using common knowledge and experience, develop documentation of the analysis. An important feature of this method is its cyclicality, which means that it should be carried out at every phase of the lifecycle of a railway product, as well as after introducing significant modifications to this product that may affect the change in safety requirements. It can be used at many object levels (system, subsystem, component). Therefore, knowledge of the reliability structure of the object of analysis is required. This is especially the case for objects with a high degree of complexity, which are undoubtedly the railway systems. This, in turn, requires reference to other normative documents, such as:

- PN-EN 61078:2017-01 - Reliability Block Diagrams,

- PN-EN 61025:2007 - Fault Tree Analysis (FTA).

The presented methods can be used interchangeably, and the decomposition of the object should be made until the required level of detail in the structure of the object is achieved. Thanks to this, each individual component can be assigned specific functions and hazards and analyze the impact of specific types of failures on the local (subassembly) and global (system) effect [1, 6, 7].

\section{Purpose and scope of application of the analysis in the light of the PN-EN IEC 60812:2018 standard}

\section{a) Identification of failure types}

Identification of the failures types of complex objects should be made on the basis of:

- operating conditions,

- the specificity of individual components,

- operating phases,

- assumed operating time,

- impact on other components.

In the case of new components of which objects are composed, the identification of failure types can be made based on the properties and historical data of other components in technical operation. According to the proposal contained in the standard [3], the preferred 
approach to determining the types of failures is a reference to the target functionality due to possible different requirements or operating conditions.

\section{b) Identification of failure causes}

In FMEA, the causes of failure are often presented in relation to the properties of the analysis object, such as physical, mechanical, electrical, and other properties. Therefore, the reasons for the failure of a component may be, for example:

- use of material with inadequate strength properties

- incorrect installation,

- lack of concentricity,

- application of improper lubricant,

- exceeding the permissible operating parameters,

- operator errors,

- others.

\section{c) Identification of failure effects}

The effect of failure is an unexpected change in the correct operation and/or loss of functionality of the analysis object. The effect may concern the occurrence of one or more types of failures. At the component level (local), e.g.

- failure of the automatic door opening button in a vehicle may result in the need for passengers to manually/manually open the door.

On the system level (global), e.g.

- failure of the automatic door opening button in a vehicle may cause a prolonged replacement of the passenger stream and generate traffic delays.

\section{Criteria for the failure assessment}

The criteria for assessing the failure are related to three classifications, associated to its significance (degree of impact), frequency of occurrence and the possibility of earlier detection of this failure. For each classification, a project team of specialists in safety, construction, analytics, and others, sets the scale and rules for assigning the appropriate value $\mathrm{S}, \mathrm{O}, \mathrm{D}$ to a given case of failure.

This chapter focuses on the alternative classification proposed as an example in the latest version of the standard [3]. Due to the fact that this standard does not impose the need to use the same classification, the industry's current approach is most often used. This does not mean that the FMEA analysis carried out in this way will not be compatible with the latest version of the PN-EN IEC 60812:2018 standard. 


\section{a) Severity classification, $S$}

The classification of the significance of the component's failure to function properly should be based on:

- construction, the principle of operation and operating conditions of the component,

- functionality (set of implemented functions),

- established customer's requirements,

- local requirements and regulations in the object's operation area,

- scope of manufacturer's warranty.

Table 1

The example of Severity classification for the risk assessment in rail transport [3]

\begin{tabular}{||l|l||}
\hline \multicolumn{1}{|c|}{ Rank (S) } & \multicolumn{1}{c|}{ Description } \\
\hline 1 & A possible hazard may appear. No injuries expected. \\
\hline 2 & One person with minor injuries \\
\hline$:$ & $:$ \\
\hline 6 & Critical, one fatality or many people with severe injuries \\
\hline 7 & Critical, several fatalities \\
\hline 8 & Critical, many fatalities \\
\hline
\end{tabular}

\section{b) Occurrence classification, $\mathbf{O}$}

Classification of the incidence of failures can be made on the basis of:

- generally available standards such as, for example, MIL-STD-1629A [2],

- determining the impact of environmental factors, the range of mechanical and electrical loads, etc. (linear, exponential, other dependence)

- data from operational tests,

- service data,

- data on the failure of other components of a similar class.

It is important to estimate the incidence of failure for the lifetime to which this frequency applies.

Table 2

The example of Occurrence classification for the risk assessment in rail transport [3]

\begin{tabular}{||l|l||}
\hline \multicolumn{1}{|c|}{ Rank $(\mathbf{O})$} & \multicolumn{1}{c|}{ Description } \\
\hline 1 & Failure rate $(\lambda)$ less or equal to $1 / 100000$ years \\
\hline 2 & $1 / 100000$ years $>\lambda \geq 1 / 30000$ years \\
\hline 3 & $1 / 30000$ years $>\lambda \geq 1 / 10000$ years \\
\hline 4 & $1 / 10000$ years $>\lambda \geq 1 / 3000$ years \\
\hline
\end{tabular}




\section{c) Detectability classification, $\mathbf{D}$}

The possibility of earlier detection of defects can be realized at the stage of:

- designing,

- manufacturing,

- operation maintenance (corrective maintenance, preventive maintenance),

Table 3

The example of Detectability classification for the risk assessment in rail transport [3]

\begin{tabular}{||l|l||}
\hline \multicolumn{1}{|c|}{ Rank (D) } & \multicolumn{1}{c|}{ Description } \\
\hline 1 & $\begin{array}{l}\text { Avoiding the consequences is almost always possible, } \\
\text { for example, using independent technical systems }\end{array}$ \\
\hline 2 & Avoiding consistency is often possible due to favourable conditions \\
\hline 3 & Avoiding the consequences is sometimes possible due to adverse conditions \\
\hline 4 & Avoiding the consequences is almost impossible \\
\hline
\end{tabular}

\section{d) Risk matrix}

The risk matrix allows determining the relationship between the selected indicators and the level of risk. For example, tab. 4 shows the relationship between the likelihood of occurrence of failure effect and the severity.

Table 4

The example of risk matrix [3]

\begin{tabular}{||l|l|l|l|l||}
\hline \multirow{2}{*}{ Likelihood } & \multicolumn{4}{|c||}{ Severity } \\
\cline { 2 - 5 } & \multicolumn{1}{|c|}{ Catastrophic } & \multicolumn{1}{|c||}{ Major } & \multicolumn{1}{c||}{ Marginal } & \multicolumn{1}{c||}{ Minor } \\
\hline 5: High & Unacceptable & Unacceptable & Undesirable & Acceptable \\
\hline 4: Medium & Unacceptable & Unacceptable & Undesirable & Acceptable \\
\hline 3: Low & Unacceptable & Unacceptable & Undesirable & Acceptable \\
\hline 2: Very low & Unacceptable & Undesirable & Undesirable & Acceptable \\
\hline 1: Remote & Undesirable & Acceptable & Acceptable & Minor \\
\hline
\end{tabular}

\section{The application of the FMEA in the rail transport}

As an example of the application of FMEA analysis in rail transport, the most important aspects of the analysis were presented in relation to risk assessment of the fire protection system in the $36 \mathrm{WEb}$ type electric multiple unit.

The $36 \mathrm{WEb}$ electric multiple unit is a modern passenger vehicle consisting of three units (motor unit + trailer unit + motor unit) based on two two-axle power bogies and two 
two-axle Jacobs type bogies. Depending on the conditions: route profile, size of passenger streams, the electric multiple unit can run in multiple tractions up to three vehicles. In order to enable quick connection and disconnection, the vehicle is equipped with automatic couplings of the Scharfenberg system. The driver's cab is located at both ends of the vehicle (fig. 1).

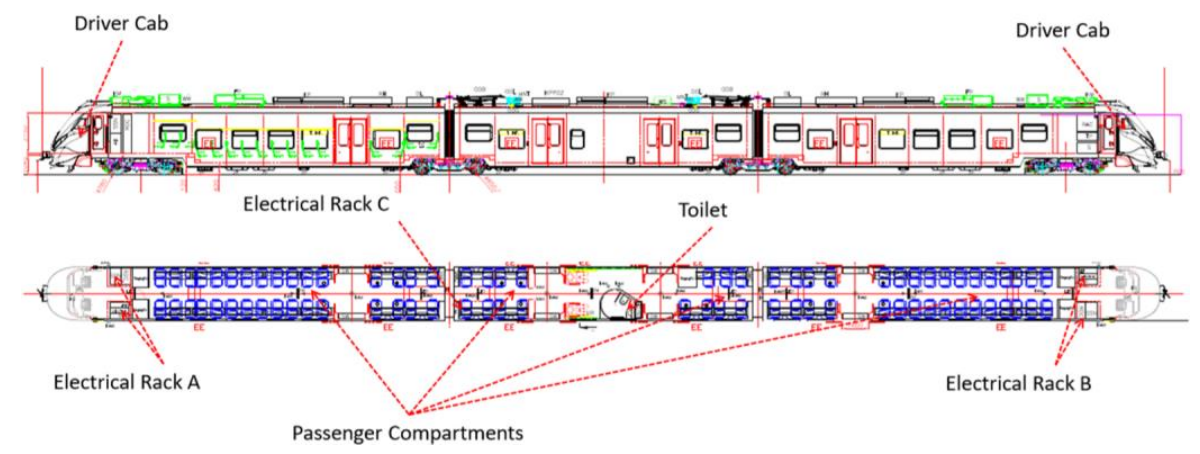

Fig. 1. Electric multiple unit type 36WEb [DTR 36Web]

The 36WEb electric multiple unit was equipped with 8 , double sliding plug doors with electric drive, 4 per side. The doors are arranged one pair for each motor unit and two pairs on the trailer unit. Given that the vehicle is made as low-floor, the floor in the entry area is at $620 \mathrm{~mm}$ from the railhead. In addition, to enable people in wheelchairs to travel (the middle section), it is equipped with devices to facilitate getting them on and off, and the passenger part has been adapted to disabled people.

Among the innovative technical solutions, fire control and containment system that meets the requirements of the standard [4] has been installed in the vehicle. The standards specify the requirements for the possibility of continuing driving in the event of a fire onboard the vehicle. It defines technical measures, the application of which will contribute to ensuring compliance with Directive 2008/57/EC and the relevant technical specifications for interoperability (TSI).

The fire protection system (FPS) used in the 36WEb type electric multiple unit consists of the three subsystems:

a) FPK - Fire Detection Kit. The subsystem consists of a control unit, temperature sensors, smoke, flame as well as servomotors and a junction box. The subsystem generates an alarm signal and activates fire-fighting measures provided by the other subsystems.

b) WSK - Water Suppression Kit. The subsystem consists of a water supply unit, section valves, nozzles and check valves. Its task is to provide fire protection to persons in the passenger compartment, including those in the toilet and service staff in the driver's cabs.

c) GEK - Gas Extinction Unit. The subsystem consists of extinction units and nozzles. Its task is to secure the electrical racks.

The FPS is responsible for performing the following functions: 
F1 - fire detection,

F2 - protecting passenger compartments with toilet cabins,

F3 - protecting electrical racks with the appropriate chemicals.

Failure to control the system and limit the spread of fire can lead to the following hazards:

H1 - severe fault - total loss of functionality,

H2 - loss of alarm signalling function,

H3 - partly loss of fire detection function (loss of protection in one or more areas of a train),

H4 - fire extinguishing function partially violated (loss of extinguishing function in both passenger and passenger as well as technical areas).

Based on the standard [3], the FMEA sheet was developed to assess the risk of the FPS and limit the spread of fire. Due to the large volume, only part of the developed sheet is shown in tab. 5.

The previous approach was used to determine the risk indicator, based on the product of the R, P, N parameters. 
Table 5

FMEA sheet for risk assessment for Fire Protection System (FPS)

\begin{tabular}{|c|c|c|c|c|c|c|c|c|c|c|c|c|c|c|}
\hline \multirow{2}{*}{$\begin{array}{l}\text { Syste } \\
\text { m }\end{array}$} & \multirow{2}{*}{$\begin{array}{l}\text { Sub- } \\
\text { syste } \\
\text { m }\end{array}$} & \multirow{2}{*}{$\begin{array}{c}\text { Part } \\
\text { Number }\end{array}$} & \multirow{2}{*}{$\begin{array}{l}\text { Descripti } \\
\text { on }\end{array}$} & \multirow{2}{*}{$\begin{array}{c}\text { Functi } \\
\text { on }\end{array}$} & \multirow{2}{*}{$\begin{array}{c}\text { Failure } \\
\text { Mode } \\
\text { (FM) }\end{array}$} & \multirow{2}{*}{$\begin{array}{l}\text { Failure } \\
\text { Cause }\end{array}$} & \multicolumn{2}{|c|}{ Failure Effect } & \multirow{2}{*}{\begin{tabular}{|c|}
$\begin{array}{c}\text { FM } \\
\text { failu } \\
\text { re } \\
\text { rate }\end{array}$ \\
{$[1 / h]$} \\
\end{tabular}} & \multirow{2}{*}{$\begin{array}{c}\text { Hazar } \\
\text { d }\end{array}$} & & \multirow[t]{2}{*}{ OD } & \multirow{2}{*}{\multicolumn{2}{|c|}{$\begin{array}{c}\mathbf{R P} \\
\mathbf{N}\end{array}$}} \\
\hline & & & & & & & Local & \begin{tabular}{|l|} 
System \\
\end{tabular} & & & & & & \\
\hline FPS & FDK & $\begin{array}{c}\text { DT- } \\
08186\end{array}$ & $\begin{array}{c}\text { PSM-110 } \\
\text { Module }\end{array}$ & F1 & $\begin{array}{l}\text { Power } \\
\text { fault }\end{array}$ & $\begin{array}{l}\text { Input } \\
\text { Voltage } \\
\text { Fail }\end{array}$ & $\begin{array}{c}\text { Loss of } \\
\text { PSM }\end{array}$ & \begin{tabular}{|c|} 
System \\
not \\
Availab \\
le \\
\end{tabular} & $\begin{array}{l}3.52 \\
\text { E-07 }\end{array}$ & H1 & 8 & 13 & 2 & 24 \\
\hline FPS & FDK & $\begin{array}{c}\text { DT- } \\
08186\end{array}$ & $\begin{array}{c}\text { PSM-110 } \\
\text { Module }\end{array}$ & F1 & $\begin{array}{l}\text { Power } \\
\text { fault }\end{array}$ & $\begin{array}{c}\text { Output } \\
\text { Voltage } \\
+24 \mathrm{~V} \text { Fail }\end{array}$ & $\begin{array}{c}\text { Output } \\
\text { power } \\
\text { loss }\end{array}$ & \begin{tabular}{|c|} 
System \\
not \\
Availab \\
le \\
\end{tabular} & \begin{tabular}{r|}
1.86 \\
E-07
\end{tabular} & $\mathrm{H} 1$ & 8 & 13 & 2 & 24 \\
\hline FPS & FDK & $\begin{array}{c}\text { DT- } \\
08186\end{array}$ & $\begin{array}{c}\text { PSM-110 } \\
\text { Module }\end{array}$ & F1 & $\begin{array}{l}\text { Power } \\
\text { Good } \\
\text { fault }\end{array}$ & $\begin{array}{l}\text { Power } \\
\text { Good } \\
\text { Circuit } \\
\text { stucked } \\
\text { Zero }\end{array}$ & $\begin{array}{c}\text { Loss of } \\
\text { diagnost } \\
\text { ic }\end{array}$ & $\begin{array}{c}\text { Loss of } \\
\text { diagnost } \\
\text { ic }\end{array}$ & \begin{tabular}{|c|}
2.99 \\
E-09
\end{tabular} & - & 6 & 13 & $3 \mid 1$ & 18 \\
\hline FPS & FDK & $\begin{array}{c}\text { DT- } \\
08186\end{array}$ & $\begin{array}{c}\text { PSM-110 } \\
\text { Module }\end{array}$ & F1 & $\begin{array}{l}\text { Power } \\
\text { Good } \\
\text { fault }\end{array}$ & $\begin{array}{l}\text { Power } \\
\text { Good } \\
\text { Circuit } \\
\text { stucked } \\
\text { One }\end{array}$ & $\begin{array}{c}\text { Loss of } \\
\text { diagnost } \\
\text { ic }\end{array}$ & $\begin{array}{c}\text { Loss of } \\
\text { diagnost } \\
\text { ic }\end{array}$ & $\begin{array}{c}7.81 \\
\text { E-09 }\end{array}$ & - & 6 & 13 & 3 & 18 \\
\hline FPS & FDK & $\begin{array}{c}\text { DT- } \\
08186\end{array}$ & $\begin{array}{c}\text { PSM-110 } \\
\text { Module }\end{array}$ & F1 & $\begin{array}{l}\text { Power } \\
\text { fault }\end{array}$ & $\begin{array}{l}\text { Output } \\
\text { Voltage } \\
\text { 5Vi Fail }\end{array}$ & $\begin{array}{c}\text { Output } \\
\text { power } \\
\text { loss }\end{array}$ & \begin{tabular}{|c|} 
System \\
not \\
Availab \\
le \\
\end{tabular} & $\begin{array}{l}4.96 \\
\text { E-08 }\end{array}$ & - & 8 & 13 & 2 & 24 \\
\hline FPS & FDK & $\begin{array}{c}\text { DT- } \\
08187\end{array}$ & $\begin{array}{c}\text { CPM-213 } \\
\text { Module }\end{array}$ & F1 & $\begin{array}{c}\text { USB } \\
\text { Detectio } \\
\text { n Circuit } \\
\text { Fail }\end{array}$ & $\begin{array}{c}\text { Detection } \\
\text { Circuit of } \\
\text { USB } \\
\text { interface } \\
\text { fail } \\
\end{array}$ & $\begin{array}{c}\text { Loss of } \\
\text { diagnost } \\
\text { ic }\end{array}$ & $\begin{array}{c}\text { Loss of } \\
\text { diagnost } \\
\text { ic }\end{array}$ & $\begin{array}{l}2.26 \\
\text { E-09 }\end{array}$ & - & 6 & 13 & 3 & 18 \\
\hline FPS & FDK & $\begin{array}{c}\text { DT- } \\
08187\end{array}$ & $\begin{array}{c}\text { CPM-213 } \\
\text { Module }\end{array}$ & $\mathrm{F} 1$ & $\begin{array}{c}\text { Conf. ID } \\
\text { Fail }\end{array}$ & $\begin{array}{c}\text { Configurati } \\
\text { on ID fail }\end{array}$ & $\begin{array}{l}\text { loss of } \\
\text { CPM }\end{array}$ & \begin{tabular}{|c|} 
System \\
not \\
Availab \\
le \\
\end{tabular} & $\begin{array}{l}8.14 \\
\text { E-09 }\end{array}$ & $\mathrm{H} 1$ & 8 & 13 & 3 & 24 \\
\hline FPS & FDK & $\begin{array}{c}\text { DT- } \\
08187\end{array}$ & $\begin{array}{c}\text { CPM-213 } \\
\text { Module }\end{array}$ & F1 & $\begin{array}{l}\text { Power } \\
\text { fault }\end{array}$ & $\begin{array}{c}\text { Input } \\
\text { power } \\
\text { Fault } \\
(24 \mathrm{Vg}) \\
\end{array}$ & $\begin{array}{l}\text { loss of } \\
\text { CPM }\end{array}$ & \begin{tabular}{|c|} 
System \\
not \\
Availab \\
le \\
\end{tabular} & \begin{tabular}{|c|}
6.83 \\
E-09
\end{tabular} & H1 & 8 & 13 & 3 & 24 \\
\hline FPS & FDK & $\begin{array}{c}\text { DT- } \\
08187\end{array}$ & $\begin{array}{c}\text { CPM-213 } \\
\text { Module }\end{array}$ & $\mathrm{F} 1$ & $\begin{array}{c}\text { Power } \\
\text { Diagnos } \\
\text { tic Fault }\end{array}$ & \begin{tabular}{|c|} 
Input \\
Power \\
diagnostic \\
circuit fault \\
$(24 \mathrm{Vg})$ \\
\end{tabular} & $\begin{array}{c}\text { loss of } \\
\text { CPM }\end{array}$ & $\begin{array}{c}\text { System } \\
\text { not } \\
\text { Availab } \\
\text { le }\end{array}$ & \begin{tabular}{|l|}
3.73 \\
E-09
\end{tabular} & $\mathrm{H} 1$ & 8 & 13 & 3 & 24 \\
\hline FPS & FDK & $\begin{array}{c}\text { DT- } \\
08187\end{array}$ & $\begin{array}{c}\text { CPM-213 } \\
\text { Module }\end{array}$ & $\mathrm{F} 1$ & $\begin{array}{l}\text { Power } \\
\text { fault }\end{array}$ & $\begin{array}{c}\text { Logical } \\
\text { power fault } \\
(3.3 \mathrm{Vi})\end{array}$ & $\begin{array}{l}\text { loss of } \\
\text { CPM }\end{array}$ & \begin{tabular}{|c|} 
System \\
not \\
Availab \\
le \\
\end{tabular} & \begin{tabular}{c|}
3.51 \\
E-08
\end{tabular} & $\mathrm{H} 1$ & 8 & 13 & 3 & 24 \\
\hline
\end{tabular}




\section{Conclusion}

The paper presents an application example of FMEA analysis according to the new approach proposed in the PN-EN IEC 60812:2018-12 standard. As an object of analysis, a fire protection system (FPS) was used to control and limit the spread of fire of a rail vehicle. The analysis showed that the RPN index values do not exceed the critical value of 100 in accordance with the said standard. It follows that taking preventive measures to reduce the risk of hazards is not necessary. The system is considered safe.

\section{References}

1. Kardach M., Fuć P., Galant M., Maciejewska M.: Risk assessment of remotely piloted aircraft systems. Journal of KONBiN, Vol. 49, Iss. 1, 2019, DOI 10.2478/jok-20190005.

2. MIL-STD-1629A, Military Standard: Procedures for Performing a Failure Mode, Efects, and Criticality Analysis, 24 Nov. 1980.

3. PN-EN IEC 60812:2018-12. Techniki analizy nieuszkadzalności systemów Procedura analizy rodzajów i skutków uszkodzeń (FMEA).

4. PN-EN 50553:2012. Zastosowanie kolejowe - Wymagania dotyczące zdolności do jazdy w przypadku pożaru na pokładzie taboru.

5. PN-EN 50126-1:2018-02. Zastosowania kolejowe - Specyfikowanie i wykazywanie niezawodności, dostępności, podatności utrzymaniowej i bezpieczeństwa (RAMS) Część 2: Sposoby podejścia do bezpieczeństwa.

6. Szkoda M., Kaczor G.: Analiza przyczyn i skutków uszkodzeń (FMEA) w zastosowaniu do pojazdów szynowych. Pojazdy Szynowe Nr 2/2014.

7. Szkoda M., Satora M.: Zastosowanie analizy przyczyn i skutków uszkodzeń (FMEA) do oceny ryzyka zmian w systemie utrzymania kolejowych środków transportu. Technical Transactions, Czasopismo Techniczne: Mechanika, Vol. 116, Iss. 8, 2019. 


\section{ZASTOSOWANIE METODY FMEA DO OCENY RYZYKA W TRANSPORCIE KOLEJOWYM ZGODNIE Z WYMAGANIAMI NORMY PN-EN IEC 60812:2018-12}

\section{Wprowadzenie}

Metoda analizy rodzajów i skutków niezdatności w sektorze transportu kolejowego (ang. Failure Mode and Effects Analysis, FMEA) pełni istotną funkcję w opracowywaniu dowodów spełniania wymagań bezpieczeństwa wyrobów (pojazdy, infrastruktura, urządzenia sterowania ruchem), szczególnie na etapie projektowania. Jest proponowanym narzędziem w procedurze RAMS wg normy [5]. Stanowi systematyczne podejście do identyfikacji przyczyn i skutków potencjalnych niezdatności na poziomie lokalnym (podzespół), jak i globalnym (system). Metoda ta wymaga zaangażowania zespołu interdyscyplinarnego (konstruktorzy, inżynierowie ds. bezpieczeństwa, analitycy, inni), którzy wykorzystując wspólną wiedzę i doświadczenie, opracowują dokumentację analizy. Istotną cechą tej metody jest jej cykliczność, co oznacza, że powinna być ona przeprowadzana w każdej fazie cyklu istnienia wyrobu kolejowego, a także po wprowadzeniu znaczących modyfikacji tego wyrobu, które mogą mieć wpływ na zmianę wymagań bezpieczeństwa. Można ją stosować na wielu poziomach obiektu (system, podsystem, element), w związku z czym wymagana jest znajomość struktury niezawodnościowej przedmiotu analizy. Ma to miejsce szczególnie w przypadku obiektów o wysokim stopniu złożoności, a takimi niewątpliwie są systemy kolejowe. Wymaga to z kolei odwołania do innych dokumentów normatywnych, takich jak:

- PN-EN 61078:2017-01 - wersja angielska. Schematy blokowe niezawodności,

- PN-EN 61025:2007 - wersja angielska. Analiza drzewa niezdatności (FTA).

Przedstawione metody mogą być stosowane zamiennie, a dekompozycja obiektu powinna być wykonana do momentu osiągnięcia wymaganego poziomu szczegółowości konstrukcji obiektu. Dzięki temu, każdemu pojedynczemu elementowi można przypisać określone funkcje i zagrożenia oraz przeanalizować wpływ konkretnych rodzajów niezdatności na skutek lokalny (podzespół) oraz globalny (system) [1, 6, 7]. 


\section{Cel i zakres stosowania analizy w świetle normy PN-EN IEC 60812:2018}

\section{a) Identyfikacja rodzajów niezdatności}

Identyfikacja rodzajów niezdatności złożonych obiektów powinna być dokonywana na podstawie:

- warunków eksploatacji,

- specyfiki poszczególnych elementów,

- faz eksploatacji,

- założonego czasu eksploatacji,

- oddziaływania na inne elementy.

W przypadku nowych elementów, z których złożone są obiekty, identyfikacja rodzajów niezdatności może być dokonana w oparciu o właściwości i dane historyczne innych elementów, będących w eksploatacji technicznej. Według propozycji zawartej w normie [3], preferowane podejście do określania rodzajów niezdatności to odniesienie do docelowej funkcjonalności z uwagi na możliwe odmienne wymagania, czy warunki eksploatacji.

\section{b) Identyfikacja przyczyn niezdatności}

W analizie FMEA, przyczyny niezdatności są często przedstawiane w odniesieniu do właściwości obiektu analizy, takich jak: właściwości fizyczne, mechaniczne, elektryczne, inne. W związku z tym, przyczynami niezdatności elementu mogą być np.:

- zastosowanie materiału o nieodpowiednich właściwościach wytrzymałościowych,

- błędny montaż,

- brak współosiowości,

- użycie niewłaściwego środka smarnego,

- przekroczenie dopuszczalnych parametrów eksploatacyjnych,

- błąd operatora,

- inne.

\section{c) Identyfikacja skutków niezdatności}

Skutek niezdatności to nieoczekiwane zmiany poprawnego działania i/lub utraty funkcjonalności obiektu analizy. Skutek może dotyczyć wystąpienia jednego lub więcej rodzajów niezdatności. Na poziomie elementu (lokalnie), np.:

- niezdatność przycisku otwarcia drzwi automatycznych w pojeździe może powodować konieczność manualnego/ręcznego otwarcia drzwi przez pasażerów.

Na poziomie obiektu (globalnie), np.:

- niezdatność przycisku otwarcia drzwi automatycznych w pojeździe może powodować wydłużoną wymianę potoku pasażerów i generować opóźnienia w ruchu. 


\section{Kryteria oceny niezdatności}

Kryteria oceny niezdatności odnoszą się do trzech klasyfikacji, związanych z jej znaczeniem (stopniem oddziaływania), częstością występowania oraz możliwością wcześniejszego wykrycia tej niezdatności. Dla każdej z klasyfikacji, zespół projektowy składający się ze specjalistów z zakresu bezpieczeństwa, konstrukcji, analityki i innych, ustala skalę oraz zasady przyporządkowywania odpowiedniej wartości S, O, D do danego przypadku niezdatności.

W niniejszym rozdziale skupiono się na klasyfikacji alternatywnej, proponowanej jako przykład w najnowszej wersji normy [3]. Z uwagi na fakt, że norma ta nie narzuca konieczności posługiwania się identyczną klasyfikacją, w przemyśle najczęściej stosuje się dotychczasowe podejścia. Nie oznacza to, że prowadzona w ten sposób analiza FMEA będzie niezgodna z najnowszą wersją standardu PN-EN IEC 60812:2018.

\section{a) Klasyfikacja znaczenia niezdatności (Severity)}

Klasyfikacja znaczenia niezdatności elementu dla poprawnego działania systemu powinna być dokonana w oparciu o:

- budowę, zasadę działania i warunki eksploatacji elementu,

- funkcjonalność (zbiór realizowanych funkcji),

- ustalone wymagania klienta,

- lokalne wymagania i przepisy na obszarze eksploatacji obiektu,

- zakres gwarancji producenta.

Tabela 1

Przykład klasyfikacji wskaźnika Severity (S) do klasyfikacji zagrożeń w transporcie kolejowym wg [3]

\begin{tabular}{||l|l||}
\hline $\begin{array}{c}\text { Ranking znaczenia } \\
\text { niezdatności (S) }\end{array}$ & \multicolumn{1}{c|}{ Opis } \\
\hline 1 & $\begin{array}{l}\text { Możliwe pojawienie się nieznaczącego zagrożenia. Brak spodziewanych } \\
\text { obrażeń dla ludzi. }\end{array}$ \\
\hline 2 & Jedna osoba z niewielkimi obrażeniami \\
\hline$:$ & $:$ \\
\hline 6 & Krytyczne, jedna ofiara śmiertelna lub wiele osób z ciężkimi obrażeniami \\
\hline 7 & Katastrofalne, kilka ofiar śmiertelnych \\
\hline 8 & Katastrofalne, wiele ofiar śmiertelnych \\
\hline
\end{tabular}

\section{b) Wskaźnik Occurence}

Klasyfikacja częstości występowania niezdatności może być dokonana na podstawie:

- ogólnodostępnych standardów, takich jak np. MIL-STD-1629A [2], 
- ustalenie wpływu czynników środowiskowych, zakresu obciążeń mechanicznych, elektrycznych, itd. (zależność liniowa, wykładnicza, inna)

- dane z testów/prób eksploatacyjnych,

- dane serwisowe,

- dane dotyczące niezdatności innych elementów podobnej klasy.

Istotne dla oszacowania częstości występowania niezdatności jest podanie czasu eksploatacji, do którego ta częstość się odnosi.

Tabela 2

\section{Przykład klasyfikacji wskaźnika Occurence (O) dla zastosowań kolejowych wg [3]}

\begin{tabular}{||l|l||}
\hline $\begin{array}{c}\text { Ranking } \\
\text { częstości } \\
(\mathbf{O})\end{array}$ & \multicolumn{1}{c|}{ Opis } \\
\hline 1 & Częstość występowania $(\lambda)$ mniejsza lub równa 1 na 100000 lat \\
\hline 2 & $1 / 100000$ lat $>\lambda \geq 1 / 30000$ lat \\
\hline 3 & $1 / 30000$ lat $>\lambda \geq 1 / 10000$ lat \\
\hline 4 & $1 / 10000$ lat $>\lambda \geq 1 / 3000$ lat \\
\hline
\end{tabular}

\section{c) Wskaźnik Detectability}

Możliwości wcześniejszego wykrycia niezdatności może być zrealizowana na etapie:

- projektowania,

- produkcji (wytwarzania),

- eksploatacji (obsługa bieżąca, obsługa planowa).

Tabela 3

Przykład klasyfikacji wskaźnika Dectability (D) dla zastosowań kolejowych wg [3]

\begin{tabular}{||l|l||}
\hline $\begin{array}{c}|c| \\
\text { Ranking } \\
\text { wykrywalności } \\
\text { (D) }\end{array}$ & \multicolumn{1}{c|}{ Opis } \\
\hline 1 & $\begin{array}{l}\text { Uniknięcie konsekwencji jest praktycznie zawsze możliwe, na przykład } \\
\text { za pomocą niezależnych systemów technicznych }\end{array}$ \\
\hline 2 & $\begin{array}{l}\text { Uniknięcie konsekwencji jest często możliwe ze względu na sprzyjające } \\
\text { warunki }\end{array}$ \\
\hline 3 & $\begin{array}{l}\text { Uniknięcie konsekwencji jest niekiedy możliwe ze względu na niesprzyjające } \\
\text { warunki }\end{array}$ \\
\hline 4 & Uniknięcie konsekwencji jest praktycznie niemożliwe \\
\hline
\end{tabular}




\section{d) Macierz ryzyka}

Macierz ryzyka pozwala określić związek między wybranymi wskaźnikami a poziomem ryzyka. Przykładowo, w tab. 4 przedstawiono związek między prawdopodobieństwem wystąpienia niezdatności a poziomem znaczenia (dla odbiorcy).

\section{Tabela 4}

\section{Przykład macierzy ryzyka wg [3]}

\begin{tabular}{||l|l|l|l|l||}
\hline \multirow{2}{*}{ Prawdopodobieństwo } & \multicolumn{4}{|c|}{ Poziom znaczenia } \\
\cline { 2 - 5 } & \multicolumn{1}{|c|}{ Katastrofalne } & \multicolumn{1}{|c|}{ Poważne } & \multicolumn{1}{c|}{ Marginalne } & Nieznaczące \\
\hline 5: Wysokie & Nieakceptowalne & Nieakceptowalne & Niepożądane & Akceptowalne \\
\hline 4: Średnie & Nieakceptowalne & Nieakceptowalne & Niepożądane & Akceptowalne \\
\hline 3: Niskie & Nieakceptowalne & Nieakceptowalne & Niepożądane & Akceptowalne \\
\hline 2: Bardzo niskie & Nieakceptowalne & Niepożądane & Niepożądane & Akceptowalne \\
\hline 1: Mało prawdopodobne & Niepożądane & Akceptowalne & Akceptowalne & Mało znaczące \\
\hline
\end{tabular}

\section{Przykład aplikacji analizy FMEA}

W ramach przykładu zastosowania analizy FMEA w transporcie kolejowym przedstawiono najistotniejsze aspekty analizy w odniesieniu do oceny ryzyka systemu kontroli i ograniczenia rozprzestrzeniania się pożaru w elektrycznym zespole trakcyjnym typu 36WEb.

Elektryczny zespół trakcyjny 36WEb to nowoczesny pojazd pasażerski składający się z trzech członów (człon napędny + człon toczny + człon napędny) opartych na dwóch dwuosiowych wózkach napędnych oraz na dwóch dwuosiowych wózkach tocznych typu Jacobsa. W zależności od warunków: profilu trasy, wielkości potoków pasażerów, pociąg może kursować w trakcji wielokrotnej do trzech pojazdów. W celu umożliwienia szybkiego łączenia i rozłączania pojazd wyposażono w sprzęgi automatyczne systemu Scharfenberga. Kabina maszynisty znajduje się na obydwu końcach pojazdu (rys. 1).

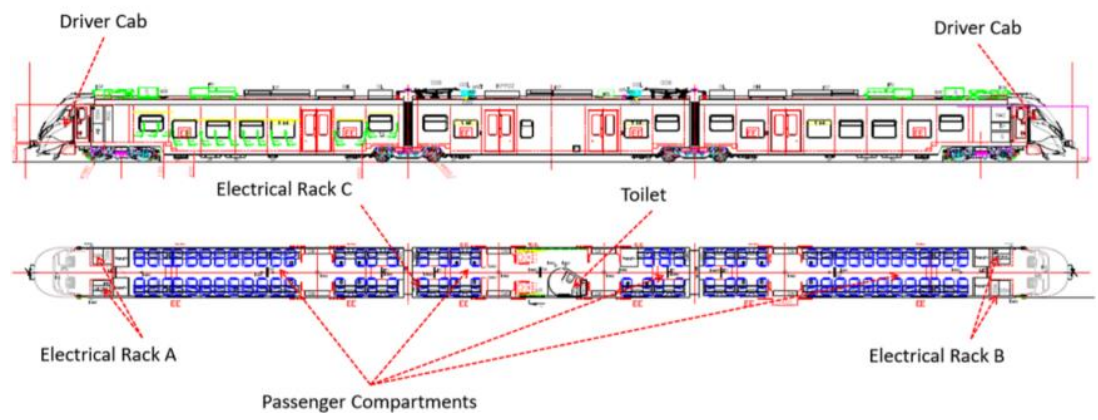

Rys. 1. Elektryczny zespół trakcyjny typu 36WEb [DTR 36Web] 
Elektryczny zespół trakcyjny 36WEb został wyposażony w 8 dwuskrzydłowych drzwi odskokowo-przesuwnych z napędem elektrycznym, po 4 na stronę. Drzwi rozmieszczone są po jednej parze dla każdego członu napędowego i dwie pary na członie tocznym. Biorąc pod uwagę, że pojazd wykonany jest jako niskopodłogowy, w strefie wejść podłoga znajduje się na poziomie $620 \mathrm{~mm}$ od poziomu główki szyny. Ponadto, w celu umożliwienia podróżowania osobom na wózkach inwalidzkich (człon środkowy), jest wyposażony w urządzenia ułatwiające wsiadanie i wysiadanie, a część pasażerska została przystosowana do podróżowania przez osoby niepełnosprawne.

Wśród innowacyjnych rozwiązań technicznych w pojeździe zainstalowano system kontroli i ograniczenia rozprzestrzeniania się pożaru spełniający wymagania normy [4]. Norma określa wymagania dotyczące możliwości kontynuowania jazdy w przypadku wybuchu pożaru na pokładzie pojazdu. Zdefiniowano w niej środki techniczne, których zastosowanie przyczyni się do zapewnienia zgodności z dyrektywą 2008/57/WE i odpowiednimi specyfikacjami technicznymi dotyczącymi interoperacyjności (TSI).

System kontroli i ograniczenia rozprzestrzeniania się pożaru (Fire Protection System, FPS) zastosowany $\mathrm{w}$ elektrycznym zespole trakcyjnym typu $36 \mathrm{WEb}$ składa się $\mathrm{z}$ trzech podsystemów:

a) Podsystem wykrywania pożaru (FPK - Fire Detection Kit). Podsystem składa się z jednostki sterującej, czujników temperatury, dymu, płomienia oraz siłowników i skrzynki przyłączeniowej. Podsystem generuje sygnał alarmowy i aktywuje środki przeciwpożarowe, zapewnione przez pozostałe podsystemy.

b) Podsystem mgły wodnej (WSK - Water Supression Kit). Podsystem składa się z jednostki zasilania wody, zaworów sekcyjnych, dysz, zaworów zwrotnych. Jego zadaniem jest ochrona przeciwpożarowa osób w przestrzeni pasażerskiej, w tym osób znajdujących się w kabinie WC oraz pracowników obsługi w kabinach maszynistów.

c) Podsystem gaszenia gazem (GEK - Gas Extintion Unit). Podsystem składa się z jednostek wygaszających oraz dysz. Jego zadaniem jest zabezpieczenie tzw. szaf elektrycznych.

System kontroli i ograniczenia rozprzestrzeniania się pożaru jest odpowiedzialny za realizację następujących funkcji:

F1 - wykrywanie pożaru,

F2 - zabezpieczanie przedziałów pasażerskich wraz z kabinami WC,

F3 - zabezpieczania szaf elektrycznych za pomocą odpowiednich środków chemicznych.

Niezdatność sytemu kontroli i ograniczenia rozprzestrzeniania się pożaru może doprowadzić do powstania następujących zagrożeń:

H1 - całkowita utrata funkcjonalności,

$\mathbf{H 2}$ - utrata funkcji sygnalizacji alarmu,

H3 - częściowo utrata funkcji wykrywania pożaru (utrata ochrony w jednym lub więcej obszarów pociągu),

H4 - funkcja gaszenia pożaru częściowo naruszona (utrata funkcji gaszenia zarówno w obszarach pasażerskich i osobowych, jak i technicznych). 
Tabela 5

Arkusz FMEA do oceny ryzyka dla systemu kontroli i ograniczenia rozprzestrzeniania się pożaru

\begin{tabular}{|c|c|c|c|c|c|c|c|c|c|c|c|c|}
\hline \multirow[t]{2}{*}{$\begin{array}{c}\text { Syste } \\
\text { m }\end{array}$} & \multirow[t]{2}{*}{$\begin{array}{c}\text { Sub- } \\
\text { syste } \\
\text { m }\end{array}$} & \multirow[t]{2}{*}{$\begin{array}{c}\text { Part } \\
\text { Number }\end{array}$} & \multirow[t]{2}{*}{$\begin{array}{l}\text { Descripti } \\
\text { on }\end{array}$} & \multirow[t]{2}{*}{$\begin{array}{l}\text { Functi } \\
\text { on }\end{array}$} & \multirow[t]{2}{*}{$\begin{array}{c}\text { Failure } \\
\text { Mode } \\
\text { (FM) }\end{array}$} & \multirow[t]{2}{*}{$\begin{array}{l}\text { Failure } \\
\text { Cause }\end{array}$} & \multicolumn{2}{|c|}{ Failure Effect } & \multirow[t]{2}{*}{\begin{tabular}{|c|} 
FM \\
failu \\
re \\
rate \\
{$[1 / \mathbf{h}]$} \\
\end{tabular}} & \multirow[t]{2}{*}{$\begin{array}{c}\text { Hazar } \\
\text { d }\end{array}$} & \multirow[t]{2}{*}{$\mathbf{S} \mathbf{O}$} & \multirow[t]{2}{*}{$\begin{array}{c}\mathbf{R P} \\
\mathbf{N}\end{array}$} \\
\hline & & & & & & & Local & System & & & & \\
\hline FPS & FDK & $\begin{array}{c}\text { DT- } \\
08186\end{array}$ & $\begin{array}{c}\text { PSM-110 } \\
\text { Module }\end{array}$ & F1 & $\begin{array}{l}\text { Power } \\
\text { fault }\end{array}$ & $\begin{array}{c}\text { Input } \\
\text { Voltage } \\
\text { Fail }\end{array}$ & $\begin{array}{c}\text { Loss of } \\
\text { PSM }\end{array}$ & $\begin{array}{c}\text { System } \\
\text { not } \\
\text { Availab } \\
\text { le }\end{array}$ & \begin{tabular}{|l|}
3.52 \\
E-07
\end{tabular} & $\mathrm{H} 1$ & \begin{tabular}{l|l|l}
8 & 1 & 3
\end{tabular} & 24 \\
\hline FPS & FDK & $\begin{array}{c}\text { DT- } \\
08186\end{array}$ & $\begin{array}{c}\text { PSM-110 } \\
\text { Module }\end{array}$ & F1 & $\begin{array}{l}\text { Power } \\
\text { fault }\end{array}$ & $\begin{array}{c}\text { Output } \\
\text { Voltage } \\
+24 \text { V Fail }\end{array}$ & $\begin{array}{c}\text { Output } \\
\text { power } \\
\text { loss }\end{array}$ & $\begin{array}{c}\text { System } \\
\text { not } \\
\text { Availab } \\
\text { le } \\
\end{array}$ & \begin{tabular}{|l|}
1.86 \\
E-07
\end{tabular} & $\mathrm{H} 1$ & \begin{tabular}{l|l|l}
8 & 1 & 3
\end{tabular} & 24 \\
\hline FPS & FDK & $\begin{array}{c}\text { DT- } \\
08186\end{array}$ & $\begin{array}{c}\text { PSM-110 } \\
\text { Module }\end{array}$ & F1 & $\begin{array}{l}\text { Power } \\
\text { Good } \\
\text { fault }\end{array}$ & $\begin{array}{c}\text { Power } \\
\text { Good } \\
\text { Circuit } \\
\text { stucked } \\
\text { Zero } \\
\end{array}$ & $\begin{array}{c}\text { Loss of } \\
\text { diagnost } \\
\text { ic }\end{array}$ & $\begin{array}{c}\text { Loss of } \\
\text { diagnost } \\
\text { ic }\end{array}$ & \begin{tabular}{|l|}
2.99 \\
E-09
\end{tabular} & - & \begin{tabular}{l|l|l}
6 & 1 & 3
\end{tabular} & 18 \\
\hline FPS & FDK & $\begin{array}{c}\text { DT- } \\
08186\end{array}$ & $\begin{array}{c}\text { PSM-110 } \\
\text { Module }\end{array}$ & $\mathrm{F} 1$ & $\begin{array}{l}\text { Power } \\
\text { Good } \\
\text { fault }\end{array}$ & $\begin{array}{c}\text { Power } \\
\text { Good } \\
\text { Circuit } \\
\text { stucked } \\
\text { One } \\
\end{array}$ & $\begin{array}{c}\text { Loss of } \\
\text { diagnost } \\
\text { ic }\end{array}$ & $\begin{array}{c}\text { Loss of } \\
\text { diagnost } \\
\text { ic }\end{array}$ & \begin{tabular}{|l|}
7.81 \\
E-09
\end{tabular} & - & \begin{tabular}{l|l|l}
6 & 1 & 3
\end{tabular} & 18 \\
\hline FPS & FDK & $\begin{array}{c}\text { DT- } \\
08186\end{array}$ & $\begin{array}{c}\text { PSM-110 } \\
\text { Module }\end{array}$ & F1 & $\begin{array}{l}\text { Power } \\
\text { fault }\end{array}$ & $\begin{array}{l}\text { Output } \\
\text { Voltage } \\
5 \text { Vi Fail }\end{array}$ & $\begin{array}{c}\text { Output } \\
\text { power } \\
\text { loss }\end{array}$ & $\begin{array}{c}\text { System } \\
\text { not } \\
\text { Availab } \\
\text { le } \\
\end{array}$ & \begin{tabular}{|l|}
4.96 \\
E-08
\end{tabular} & - & \begin{tabular}{l|l|l}
8 & 1 & 3
\end{tabular} & 24 \\
\hline FPS & FDK & $\begin{array}{c}\text { DT- } \\
08187\end{array}$ & $\begin{array}{c}\text { CPM-213 } \\
\text { Module }\end{array}$ & F1 & $\begin{array}{c}\text { USB } \\
\text { Detectio } \\
\text { n Circuit } \\
\text { Fail }\end{array}$ & \begin{tabular}{|c|} 
Detection \\
Circuit of \\
USB \\
interface \\
fail \\
\end{tabular} & $\begin{array}{c}\text { Loss of } \\
\text { diagnost } \\
\text { ic }\end{array}$ & $\begin{array}{c}\text { Loss of } \\
\text { diagnost } \\
\text { ic }\end{array}$ & \begin{tabular}{|l|}
2.26 \\
E-09
\end{tabular} & - & \begin{tabular}{l|l|l}
6 & 1 & 3
\end{tabular} & 18 \\
\hline FPS & FDK & $\begin{array}{c}\text { DT- } \\
08187\end{array}$ & $\begin{array}{c}\text { CPM-213 } \\
\text { Module }\end{array}$ & $\mathrm{F} 1$ & $\begin{array}{c}\text { Conf. ID } \\
\text { Fail }\end{array}$ & $\begin{array}{c}\text { Configurati } \\
\text { on ID fail }\end{array}$ & $\begin{array}{c}\text { loss of } \\
\text { CPM }\end{array}$ & $\begin{array}{c}\text { System } \\
\text { not } \\
\text { Availab } \\
\text { le }\end{array}$ & \begin{tabular}{|l|}
8.14 \\
E-09
\end{tabular} & $\mathrm{H} 1$ & \begin{tabular}{l|l|l}
8 & 1 & 3
\end{tabular} & 24 \\
\hline FPS & FDK & $\begin{array}{c}\text { DT- } \\
08187\end{array}$ & $\begin{array}{c}\text { CPM-213 } \\
\text { Module }\end{array}$ & $\mathrm{F} 1$ & $\begin{array}{c}\text { Power } \\
\text { fault }\end{array}$ & $\begin{array}{c}\text { Input } \\
\text { power } \\
\text { Fault } \\
(24 \mathrm{Vg}) \\
\end{array}$ & $\begin{array}{c}\text { loss of } \\
\text { CPM }\end{array}$ & \begin{tabular}{|c|} 
System \\
not \\
Availab \\
le \\
\end{tabular} & \begin{tabular}{|c|}
6.83 \\
E-09
\end{tabular} & H1 & \begin{tabular}{l|l|l}
8 & 1 & 3
\end{tabular} & 24 \\
\hline FPS & FDK & $\begin{array}{c}\text { DT- } \\
08187\end{array}$ & $\begin{array}{c}\text { CPM-213 } \\
\text { Module }\end{array}$ & F1 & $\begin{array}{l}\text { Power } \\
\text { Diagnos } \\
\text { tic Fault }\end{array}$ & \begin{tabular}{|c|} 
Input \\
Power \\
diagnostic \\
circuit fault \\
$(24 \mathrm{Vg})$ \\
\end{tabular} & $\begin{array}{c}\text { loss of } \\
\text { CPM }\end{array}$ & $\begin{array}{c}\text { System } \\
\text { not } \\
\text { Availab } \\
\text { le }\end{array}$ & \begin{tabular}{|l|}
3.73 \\
E-09
\end{tabular} & H1 & \begin{tabular}{l|l|l}
8 & 1 & 3
\end{tabular} & 24 \\
\hline FPS & FDK & $\begin{array}{c}\text { DT- } \\
08187\end{array}$ & $\begin{array}{c}\text { CPM-213 } \\
\text { Module }\end{array}$ & F1 & $\begin{array}{c}\text { Power } \\
\text { fault }\end{array}$ & $\begin{array}{c}\text { Logical } \\
\text { power fault } \\
(3.3 \mathrm{Vi})\end{array}$ & $\begin{array}{c}\text { loss of } \\
\text { CPM }\end{array}$ & $\begin{array}{c}\text { System } \\
\text { not } \\
\text { Availab } \\
\text { le }\end{array}$ & \begin{tabular}{|l|}
3.51 \\
E-08
\end{tabular} & $\mathrm{H} 1$ & \begin{tabular}{l|l|l}
8 & 1 & 3
\end{tabular} & 24 \\
\hline
\end{tabular}


Na podstawie standardu [3] opracowano arkusz FMEA do oceny ryzyka sytemu kontroli i ograniczenia rozprzestrzeniania się pożaru. Ze względu na znaczną objętość, w tab. 5 przedstawiono wyłącznie fragment opracowanego arkusza.

Zastosowano dotychczasowe podejście do wyznaczania wskaźnika ryzyka, opierającego się na iloczynie parametrów R, P, N.

\section{Podsumowanie}

W pracy przedstawiono przykład aplikacyjny analizy FMEA wg nowego podejścia, zaproponowanego w normie PN-EN IEC 60812:2018. Jako obiekt analizy wykorzystano system kontroli i ograniczenia rozprzestrzeniania się pożaru pojazdu szynowego. Przeprowadzona analiza wykazała, że wartości wskaźnika RPN nie przekraczają wartości krytycznej równej 100 zgodnie ze wspomnianą normą. Wynika z tego, że podejmowanie działań zapobiegawczych, mających na celu obniżenie ryzyka występowania zagrożeń nie jest konieczne. System jest uważany za bezpieczny.

\section{Literatura}

1. Kardach M., Fuć P., Galant M., Maciejewska M.: Risk assessment of remotely piloted aircraft systems. Journal of KONBiN, Vol. 49, Iss. 1, 2019, DOI 10.2478/jok-20190005.

2. MIL-STD-1629A, Military Standard: Procedures for Performing a Failure Mode, Efects, and Criticality Analysis, 24 Nov. 1980.

3. PN-EN IEC 60812:2018-12. Techniki analizy nieuszkadzalności systemów Procedura analizy rodzajów i skutków uszkodzeń (FMEA).

4. PN-EN 50553:2012. Zastosowanie kolejowe - Wymagania dotyczące zdolności do jazdy w przypadku pożaru na pokładzie taboru.

5. PN-EN 50126-1:2018-02. Zastosowania kolejowe - Specyfikowanie i wykazywanie niezawodności, dostępności, podatności utrzymaniowej i bezpieczeństwa (RAMS) Część 2: Sposoby podejścia do bezpieczeństwa.

6. Szkoda M., Kaczor G.: Analiza przyczyn i skutków uszkodzeń (FMEA) w zastosowaniu do pojazdów szynowych. Pojazdy Szynowe Nr 2/2014.

7. Szkoda M., Satora M.: Zastosowanie analizy przyczyn i skutków uszkodzeń (FMEA) do oceny ryzyka zmian w systemie utrzymania kolejowych środków transportu. Technical Transactions, Czasopismo Techniczne: Mechanika, Vol. 116, Iss. 8, 2019. 